\title{
Rip current hazard assessment on a sandy beach in Liguria, NW Mediterranean
}

\author{
Luigi Mucerino ${ }^{1,3}$ D Luca Carpi $^{1,3} \cdot$ Chiara F. Schiaffino $^{1} \cdot$ Enzo Pranzini $^{2}$. \\ Eleonora Sessa ${ }^{1} \cdot$ Marco Ferrari $^{1,3}$
}

Received: 10 April 2020 / Accepted: 2 September 2020 / Published online: 14 September 2020

(c) The Author(s) 2020

\begin{abstract}
Rip currents are one of the most significant environmental hazards for beachgoers and are of interest to coastal scientists. Several studies have been conducted to understand rip current dynamics, and several approaches for rip hazard assessment have been proposed. In general, the purpose is to provide knowledge and tools to support authorities and lifeguards in rip current risk prevention. This study proposes the application of an expeditious methodology to evaluate rip current hazard and risk, based on probability theory. The tested area was located along the Alassio beach, a renowned tourist destination located on the western Ligurian coast (NW Italy). A coastal video-monitoring system was used for rip currents individuation, whereas wave data were collected thanks to an oceanographic buoy managed by Regione Liguria. In detail, a yearly analysis was performed to identify the correspondence between rip currents and wave parameters data. The results showed that rip currents occur, in the study area, under moderate wave conditions $\left(0.5 \leq H_{s} \leq 1.34 \mathrm{~m}\right.$; $\left.4.7 \leq T_{m} \leq 7.0 \mathrm{~s} ; 150^{\circ} \mathrm{N} \leq \theta_{m} \leq 227^{\circ} \mathrm{N}\right)$. Based on this analysis, an easy application of the probability theory was applied to evaluate the level of hazard. Moreover, considering the official tourist data, we also perform an expeditious rip currents risk evaluation. The results showed that the hazard level is considered high at annual time scale and moderate during the tourist season; the risk is related to seasonal presences. The study can propose a tool to support authorities and lifeguards in water safety planning and management.
\end{abstract}

Keywords Rip current · Hazard · Video monitoring $\cdot$ Beach management · Probability

\section{Introduction}

In Europe, more than 600 million people per year go to the beach during the summer period, when most of the 27.000/year drownings in coastal waters occur (Funari et al. 2016). In Italy, the death rate is attested to be between 50 and 100 cases. In 2014, 13 fatal drownings occurred along the Ligurian coast: three of those were local beachgoers and ten

Luigi Mucerino

luigi.mucerino@edu.unige.it

Extended author information available on the last page of the article 
were tourists (Funari et al. 2016). Italy has not official database on accidents and rescue. Additional information on accident dynamics is not described. The beachgoers risk exposure theme has a key role in coastal management practice (Ferrari et al. 2019). Even though official data are rare, it is obvious many people are potentially exposed to natural hazards along the Ligurian beaches-NW Italy. Among other natural hazards in this environment, rip currents are the greatest natural hazard for beachgoers, especially along wave-dominated coasts (Austin et al. 2012). These currents "are narrow and concentrated seaward-directed flows that extend from close to the shoreline and through the surf zone and varying distances beyond" (Castelle et al. 2016). Rip current behaviour and the related risk to bathers are, to a certain extent, predictable and directly related to the nearshore dynamics (MacMahan et al. 2006). For example, intermediate sandy beaches, i.e. beaches with transverse bar morphology subjected to medium-energy wave conditions, are considered particularly conducive to rip current activity (Brander 1999; Wright and Short 1984). Rip currents can also occur near rocky shoals and coastal structures, as well as headland-embayed beaches (Scott et al. 2014). Beachgoers are exposed to drowning risk related to rip currents. This is due to a range of factors such as: unfamiliarity with the environment and associated hazards (Ballantyne et al. 2005; Clifford et al. 2018; Moran and Ferner 2017), poor swimming abilities (Drozdzewski et al. 2015; Williamson et al. 2012) and inattention when on vacation (Clifford et al. 2018; Wilks and Pendergast 2010). Every year, hundreds of people drown and tens of thousands more are rescued from rip currents globally [e.g. da F. Klein et al. (2003), Hartmann (2006), Gensini and Ashley (2010), Brewster (2010), Brighton et al. (2013), Scott et al. (2011), Kumar and Prasad (2014), Arozarena et al. (2015) and Barlas and Beji (2016)]. Rip currents are an hazard responsible for swimmers' catch and drag out seaward (Shepard et al. 1941; Short and Hogan 1994). They can quickly move swimmers spatially to regions of deeper water and greater hazard and have globally documented as a significant natural hazard (Shepard et al. 1941; Short and Hogan 1994; Short 1999). Following Leatherman (2017), rip current hazard was primarily evaluated utilizing United States Lifesaving Association (USLA) rescue statistics. These are available online and show the rescue number from rip currents for each beach USLA lifeguards is present on (United States Lifesaving Association 2013). According to the USLA, 80 per cent of all lifeguard rescues are associated with rip currents. In the Netherlands, a rip current prediction model system is being used on the basis of the bathymetry measurement along with application of the XBeach hydrodynamic model (Roelvink et al. 2009), to predict current speeds and directions in the context of Egmond beach (Van Ormondt et al. 2012). Other work Austin et al. (2012) developed a rip currents operational tool using field measurements, a twodimensional horizontal (2DH) non-stationary model and ARGUS video sensing. Certainly, Italian beaches show minor risk factors compared to the Ocean coastlines. However, particular conditions such as the presence of structures and/or particular morphologies can increase rip current hazard (Brander and MacMahan 2011). In Tuscany, part of the "Perla" project (Cooperation Program border Italy-France "Maritime" 2007-2013 founded by EU) has started an awareness process addressed to beachgoers based on the characterization of the coasts and based on beach morphological features. The University of Florence has developed a methodology to define the sectors with different safety conditions for bathing including warning signs where rip current hazard are more probable (Pranzini 2015). Rip currents events affecting Mediterranean coastlines have been described by Benassai et al. (2017), via a model chain (WaveWatchIII + XBeach), sediment grain size analysis and unmanned aerial vehicle (UAV), highlighting rip events occurrence under wave conditions with offshore wave height between 0.3 and $1.4 \mathrm{~m}$ and peak periods from 2.7 to $5.8 \mathrm{~s}$. 
The aim of this study is to propose an expeditious method to evaluate the rip currents hazard and risk. In detail, we proposed a variant to the method proposed previously (Ferrari et al. 2019), based on the probability theory. The method is tested on the Alassio beach, located on the Ligurian Western coast (Ligurian Sea, NW Italy), which is one of the most popular seaside tourist location of the continent. The stretch of coast is managed by 20 beach resorts, and beach safety is guaranteed by resorts via seasonal lifeguards. The use of remote sensing video was considered with the purpose of recording rip current flows on the Alassio beach from April 2012 to March 2013 (Murray et al. 2013). These data, together with Capo Mele buoy wave dataset, defined the most common sea conditions to trigger rip currents in Alassio beach. Moreover, two rip events (among those observed) were simulated using 2DH hydrodynamic model (XBeach). XBeach is a well-known tool for rip currents modelling (Austin et al. 2012; Van Ormondt et al. 2012), and we used it to obtain a further qualitative confirmation regarding the rip currents genesis in the study area. The results show how the proposed approach for rip currents hazard and risk assessment is easily adoptable and customizable for single study cases, and how the probabilistic approach could be easily integrated in a marine forecasts system. Moreover, the proposed method follows the basic principles for hazard and risk assessment. This research is also a useful support for local authorities and coastal managers that deal with beach safety and risk prevention.

\section{Study area}

Alassio town is one of the most popular seaside tourism destinations in Italy and Europe, and it is located on the Ligurian Western coast (NW Italy) (Fig. 1). The main shore (Fig. 1) can be described as a sandy beach on a 3-km long, NE-SW oriented coastline; the backshore is spatially limited by a promenade and a pedestrian wharf is situated in the central sector of the coastline (Fig. 1). The nearshore area, from the shoreline to $10 \mathrm{~m}$ water depth, has a slope of approximately $1.5^{\circ}$. The zone from 10 to $20 \mathrm{~m}$ of water depth is of $4.5^{\circ}$ (Bowman et al. 2007). Alassio beach is classified as dissipative $(\varepsilon>20)$ following (Vacchi et al. 2014) using surf scaling index $\varepsilon$ supplied by (Jackson et al. 2005). Rivers feeding the coastline belong to small catchments characterized by a torrential regime and mainly located on the western Liguria flyschoid Units composed of limestone, marly limestone, marls and marly siltstone (Cortesogno and Vanossi 1984; Ferrari et al. 2014).

The investigated beach is exposed to the typical Western Liguria wave climate with storms from the South (Vietti et al. 2010). The more frequent storms come from SW, but Alassio beach is partially protected by capo Mele promontory that generates strong wave diffraction. Instead, marine weather conditions from the south-west are less frequent but more incisive in the beach processes showing a significant cross-shore sediment transport (Ferrari et al. 2014). 


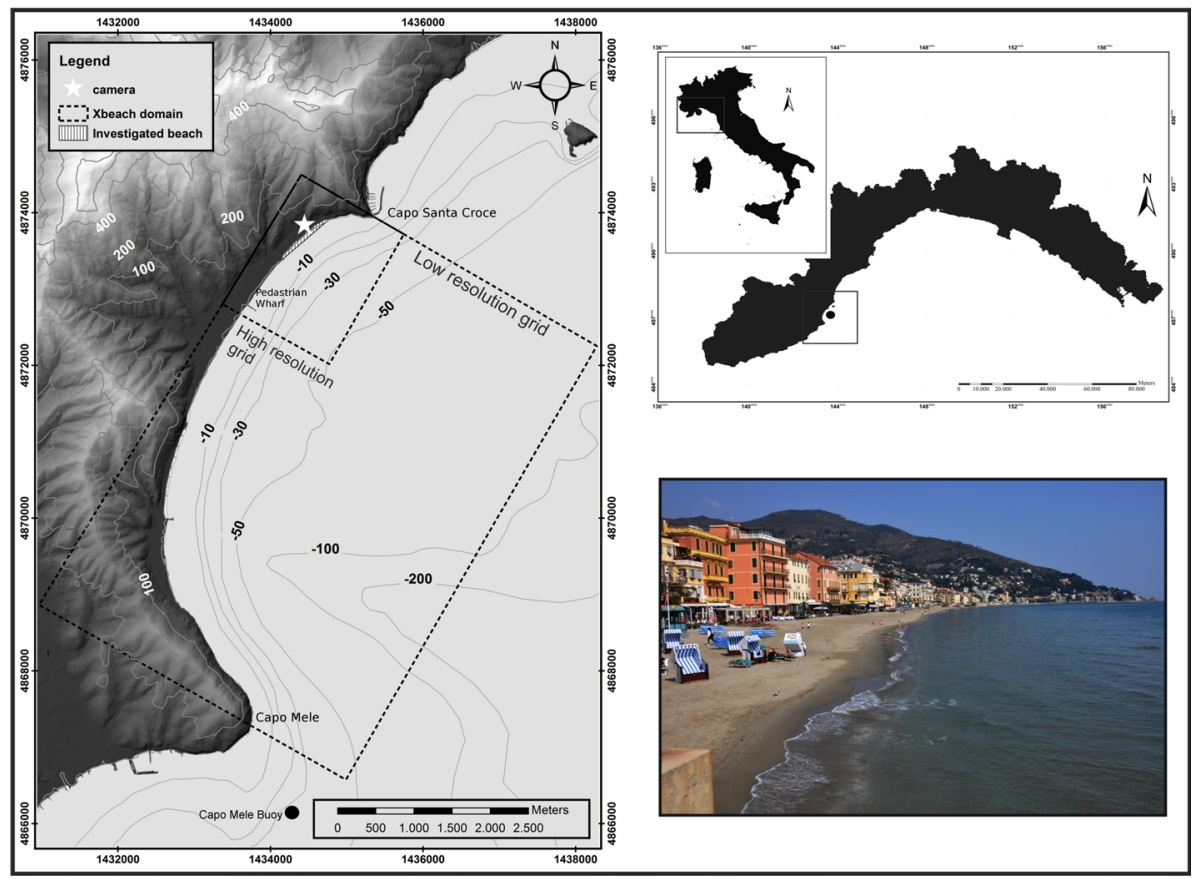

Fig. 1 Location of the study area (Alassio, NW Mediterranean on the Ligurian Western coast); XBeach domain used to evaluate wave propagation, camera position $(\star)$ and Capo Mele buoy location $(\bullet)$; photograph of the Alassio beach shoreline

\section{Methods}

\subsection{Field survey and sampling}

Dry beach profiles were surveyed using a Differential Global Position System (DGPS) in November 2011, while submerged beach morphology was acquired using single-beam echo sounder, mounted on a small boat and positioned by a Trimble real-time cinematic (RTK) GPS system. Topographic and bathymetric data have been collected along regularly spaced cross-shore transects from the emerged beach to $20 \mathrm{~m}$ water depth. Singlebeam data were corrected considering wave conditions as well as astronomical and baric tide. Bathymetries from 20 to $80 \mathrm{~m}$ in depth were supplied by the Istituto Idrografico della Marina Italiana. The morphology of the promontories was added to the dataset using the LIDAR data, acquired in 2008 (Italian Ministry of the Environmental Land and Sea, 2008-2011). These data have been subsequently merged together and interpolated onto a regular grid through GIS software, producing a Digital Terrain Model (DTM). Furthermore, wave data have been collected from Capo Mele Buoy, which is located $6.12 \mathrm{~km}$ far from the study area in correspondence to bathymetric $80 \mathrm{~m}$ (Fig. 1) and managed by ARPAL (Environmental Agency Ligurian Region). Data acquisition refers to the period comprised between April 2012 and March 2013. Buoy data were acquired every $30 \mathrm{~min}$ for significant wave heights $\left(H_{s}\right)$ (Fig. 2), mean wave period $\left(T_{m}\right)$ 


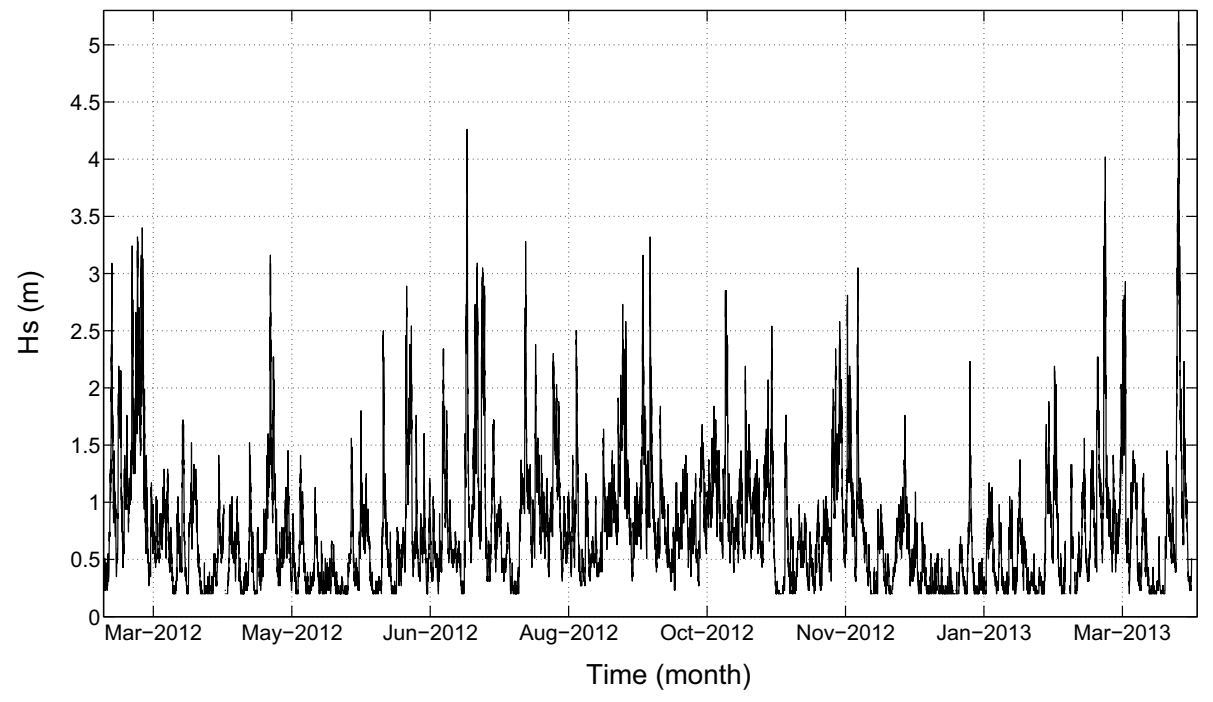

Fig. 2 Wave buoy dataset. Significant wave height dataset from March 2012 to March 2013 supplied by Capo Mele Buoy

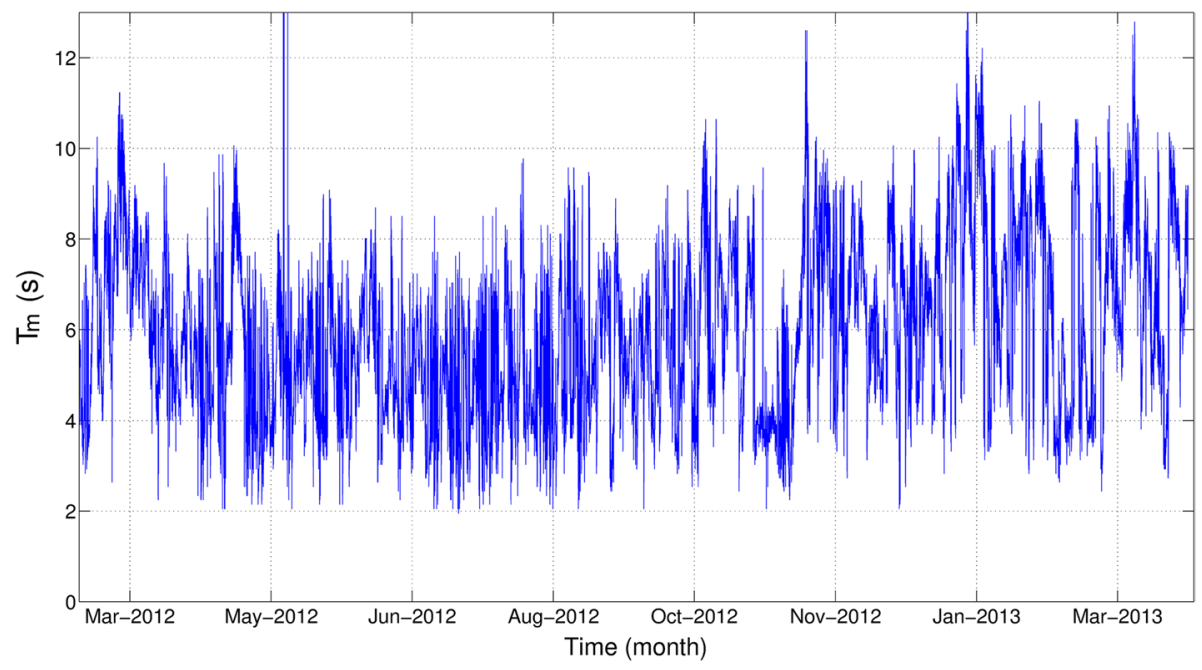

Fig. 3 Wave buoy dataset. Mean wave period dataset from March 2012 to March 2013 supplied by Capo Mele Buoy

(Fig. 3) and mean wave directions $\left(\theta_{m}\right)$ (Fig. 4). Tide data have been supplied by the official Italian tide archives (http://www.mareografico.it). 


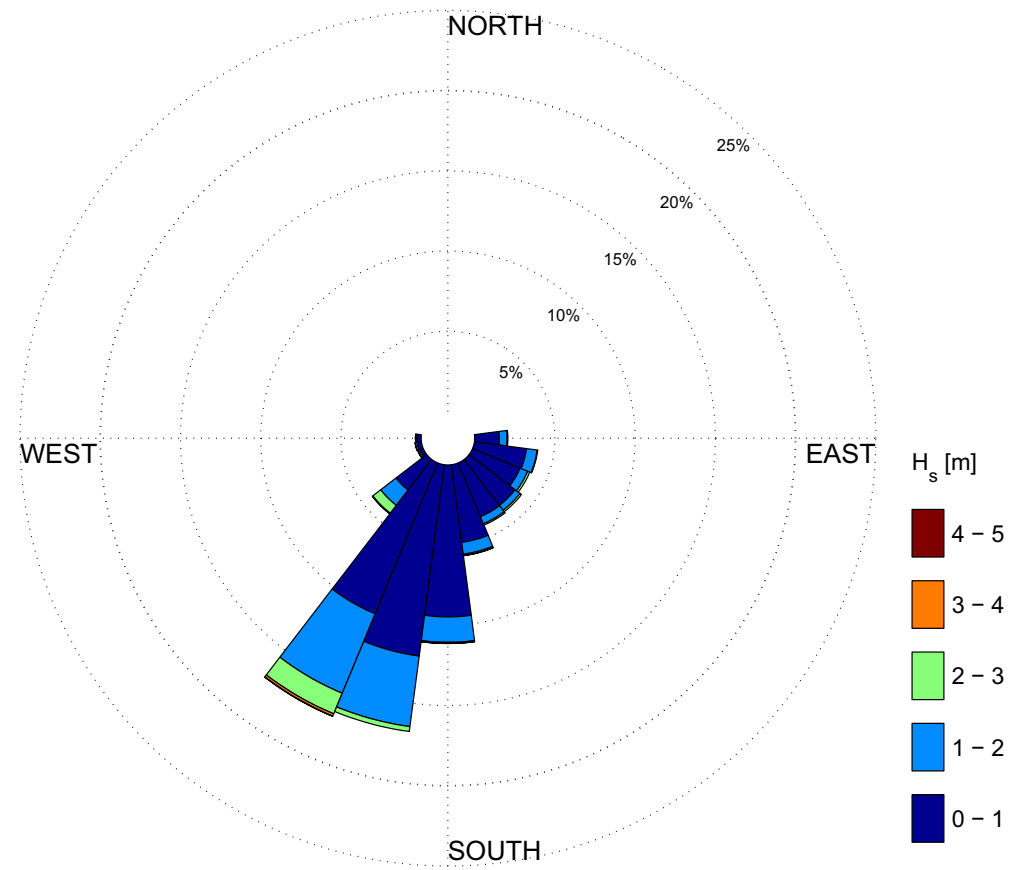

Fig. 4 Wave buoy dataset. Mean wave direction dataset from March 2012 to March2013 supplied by Capo Mele Buoy

\subsection{Video monitoring}

Images were collected by the web camera located in the northern side of the area and placed on the top of a building $25 \mathrm{~m}$ a.m.s.l. The web camera provides a view of $350 \mathrm{~m}$ of Alassio beach northern side, with $720 \times 567$ pixels resolution (Fig. 1). The system collected 120 images per hour that were successively rectified and elaborated using the Timex method. Through this study, a hydro-morphodynamic behaviour of the beach was analysed through a video monitoring system (Aarninkhof et al. 2005; Holland et al. 1997; Jiménez et al. 2007; Turner et al. 2004). Image datasets were analysed using Beachkeeper plus software (Brignone et al. 2012; Schiaffino et al. 2015), an image management tool providing Time-Exposure, Variance, Day-Timex, as suggested by the extensive coastal video monitoring literature (Aarninkhof et al. 2005; Alexander and Holman 2004; Davidson et al. 2006; Holman et al. 2003). The aim of these observations is to identify rip current flows occurring between April 2012 and March 2013 along the Alassio beach northside. We analysed 3600 Timex images, elaborated on 481800 snapshots for the year. In details, 12 Timex/day were elaborated during the period with major daylight (2160 images), while 8 Timex/day was used during the period with minor daylight (1440 images) to recognize hydrodynamic conditions with potential patterns. Flow detection from images was based on the physical consideration that the rip current produces a visible colour contrast, that is easy to detect in the surfzone when light and picture quality are adequate (Pugliano et al. 2019). 


\subsection{Rip currents modelling using XBeach}

XBeach model was used to obtain a further qualitative confirmation for rip currents occurrence in the study area. XBeach concurrently solves the time-dependent short wave action balance, roller energy equations, nonlinear shallow water equations of mass and momentum, sediment transport formulations and bed update on the scale of wave groups (Roelvink et al. 2009). A computational grid was generated merging bathymetric and topographic data described in Sect. 3.1. The ultimate computational grid was generated by optimizing the spatial resolution across the study area, which is $765 \mathrm{~m}$ for cross-shore and $1230 \mathrm{~m}$ for alongshore directions. As shown in Fig. 1, an irregular mesh was used obtaining a higher resolution on the surf zone and a lower resolution for areas far from the coastline. The grid resolution was $5 \mathrm{~m}$ on the beach and $25 \mathrm{~m}$ off the coast. Offshore wave boundary conditions were implemented using the JONSWAP spectrum (Hasselmann et al. 1980) considering the Capo Mele buoy wave data for seaward flow simulation. XBeach has a number of free parameters used to calibrate the model. For this application, parameters were modified as shown in Table 1, whereas all other parameters have been set to their recommended default value. The breaking index $(\gamma)$ has been calculated using a linear relationship with the product of local wave number and water depth (Ruessink et al. 2003); D50 and D90 values have been obtained from sedimentological analysis; bed friction has been computed using the White-Colebrook formulation, based on the relation between the D90 of the top bed layer and the geometrical roughness described previously (Nikuradse 1950) https://xbeach.readthedocs.io.

\subsection{Rip currents hazard assessment}

Hazard can be defined as "the probability of occurrence of a potentially damag-ing phenomenon within a specific period of time and within a given area" (Varnes 1984). To evaluate the rip hazard level, we propose a method based on probability theory (Ferrari et al. 2019). We considered three different hazard descriptors: (1) Significative wave height $\left(H_{s}\right)$, (2) Wave period $\left(T_{m}\right)$ and (3) Wave direction $\left(\theta_{m}^{\circ}\right)$. The hazard descriptors were combined using basic principles of probability theory (Spiegel 2008). Therefore, based on the Ferrari approach (Ferrari et al. 2019), the following equations can be written:

$$
\begin{gathered}
\left.\left(H_{s} \cap T_{m} \cap \theta_{m}^{\circ}\right)=P\left(H_{s}\right) \cap P\left(T_{m}\right) \cap \theta_{m}^{\circ}\right) \\
\left(H_{s} \cup T_{m} \cup \theta_{m}^{\circ}\right)=P\left(H_{s}\right)+P\left(T_{m}\right)+P\left(\theta_{m}^{\circ}\right)
\end{gathered}
$$

Table 1 XBeach parameters setup

\begin{tabular}{lll}
\hline XB parameters & Default value & Alassio beach value \\
\hline Breaking index $(\gamma)$ & 0.55 & 0.78 \\
D50/D90 & $0.20 / 0.30(\mathrm{~mm})$ & $0.18 / 0.13(\mathrm{~mm})$ \\
Bed friction formulation & Chezy & White-Colebrook grain-size \\
\hline
\end{tabular}

Table presents the values as modified for the investigated area simulation flows. Due to different local hydrodynamic conditions, described parameters are the result of the field survey and laboratory analysis conducted 
Table 2 Hazard descriptors (Hs, $\left.\mathrm{Tm}, \theta_{m}\right)$ and related levels based on the considered time scale

\begin{tabular}{lllll}
\hline $\begin{array}{l}\text { Hazard } \\
\text { descrip- } \\
\text { tors }\end{array}$ & Low & Moderate & High & Time scale \\
\hline$H_{s}$ & & & \\
$T_{m}$ & $<90$ days & $90 \leq$ days $\leq 180$ & $>180$ days & Yearly \\
$\theta_{m}^{\circ}$ & & & \\
$H_{s}$ & & & \\
$T_{m}$ & $<52$ days & $52 \leq$ days $\leq 77$ & $>77$ days & Tourist season \\
$\theta_{m}^{\circ}$ & & & \\
\hline
\end{tabular}

The different levels were assigned, for each hazard descriptors, based on the occurrence of wave conditions (days/year or days/tourist season) suitable for rip currents development

\begin{tabular}{lll}
\hline$R H$-Index & Hazard & Safety \\
\hline $0.01 \leq R H \leq 0.51$ & Low & High \\
$0.51<R H \leq 0.995$ & Moderate & Moderate \\
$R H>0.995$ & High & Low \\
\hline
\end{tabular}

The hazard classes and safety levels were determined based on specific conditions related to the combination of different levels of hazard descriptors

Equation 1 gives the probability that all the events will occur simultaneously, while Eq. 2 expresses the probability of a single event occurrence. The probability of occurrence of the opposite event $\bar{X}$ (i.e. probability of non-occurrence) satisfies the following equation:

$$
P(\bar{X})=1-P(X)
$$

Consequently, for each combination of the considered hazard descriptors, the rip hazard $(R H)$ was calculated by using the following formula:

$$
R H=\left[1-\left(1-P\left(H_{s}\right)\right)\left(1-P\left(T_{m}\right)\right)\left(1-P\left(\theta_{m}^{\circ}\right)\right)\right]
$$

Each hazard descriptor was quantified via three different probability values: 0.01 (low), 0.5 (moderate) and 0.99 (high). These values were assigned according to occurrence of the wave conditions (i.e. $H_{s}, T_{m}, \theta_{m}^{\circ}$ ) suitable for rip currents generation (days/ year or days/tourist season) (Table 2). The choice to consider two different time scales (e.g. yearly and tourist season) allowed a complete assessment of the probability of rip currents occurrence (i.e. rip hazard). The yearly time scale allowed one to consider a wide range of wave boundary conditions and tourist season time scale is the most relevant in terms of beach safety management. The $R H$-index furnishes information about the rip current hazard degree on a given beach. Finally, three classes of hazard were determined based on the following conditions (Table 3): 
- Low hazard $(0.01 \leq R H \leq 0.51)$ : one hazard descriptor has a moderate probability value and, instead, the other two have low probability value.

- Moderate hazard $(0.51<R H \leq 0.995)$ : at least two hazard descriptors have moderate probability value and the other one has low probability value, up to a condition where one hazard descriptor has low probability value, one has moderate probability value, and one has high probability value.

- High hazard $(R H>0.995)$ : at least two hazard descriptors have high probability value.

\subsection{Rip currents risk assessment}

Risk can be defined as a measure of the probability and severity of an adverse effect to health, property or the environment (Fell et al. 2008). Thus, if we try to obtain a rip currents risk analysis, we must identify and quantify the elements (i.e. bathers) at risk. Unfortunately, it is not possible to know the exact number of beachgoers that are on the beach at a given moment. Both for the study area and for the Italian coasts in general, control systems for beach tourists fluxes are not available at the moment. Thus, in order to obtain a quantitative evaluation of the beachgoers presence (i.e. elements at risk), we adopted the dataset of the tourist presences in 2012 for the Alassio municipality. A variable, identified as risk conditioning variable $\left(X_{0}\right)$, was defined based on tourist presences during the year (Fig. 5). Usually, tourist activities are divided into three seasons: Low, Medium and High, related to statistical tourism attendance (Fig. 5). Risk conditioning variable $\left(X_{0}\right)$ was introduced to quantify three different probability values for each season, as reported in Table 4. According to Ferrari et al. (2019), $R H$-index and risk conditioning variable $\left(X_{0}\right)$ were combined to obtain an evaluation of rip currents risk $(R R)$ on the Alassio beach (Eq. 5).

$$
R R=P\left(X_{0}\right) R H
$$

Three $R R$ classes (low risk, moderate risk and high risk) were obtained from the intersection of $R H$ and $X_{0}$. In this way, it was possible to obtain a $R R$-matrix (Fig. 9), a common approach to conducting a subjective risk assessment (Markowski and Mannan 2008) (Fig. 6).

Table 4 Risk conditioning variable $X_{0}$ related to low, medium and high Season

\begin{tabular}{ll}
\hline Season & $X_{0}$ \\
\hline Low & 0.01 \\
Medium & 0.5 \\
High & 0.99 \\
\hline
\end{tabular}

The numerical coefficients describe the probability to find people on the beach, and it is necessary to combining X0 and RH-index (through Eq. 5) 


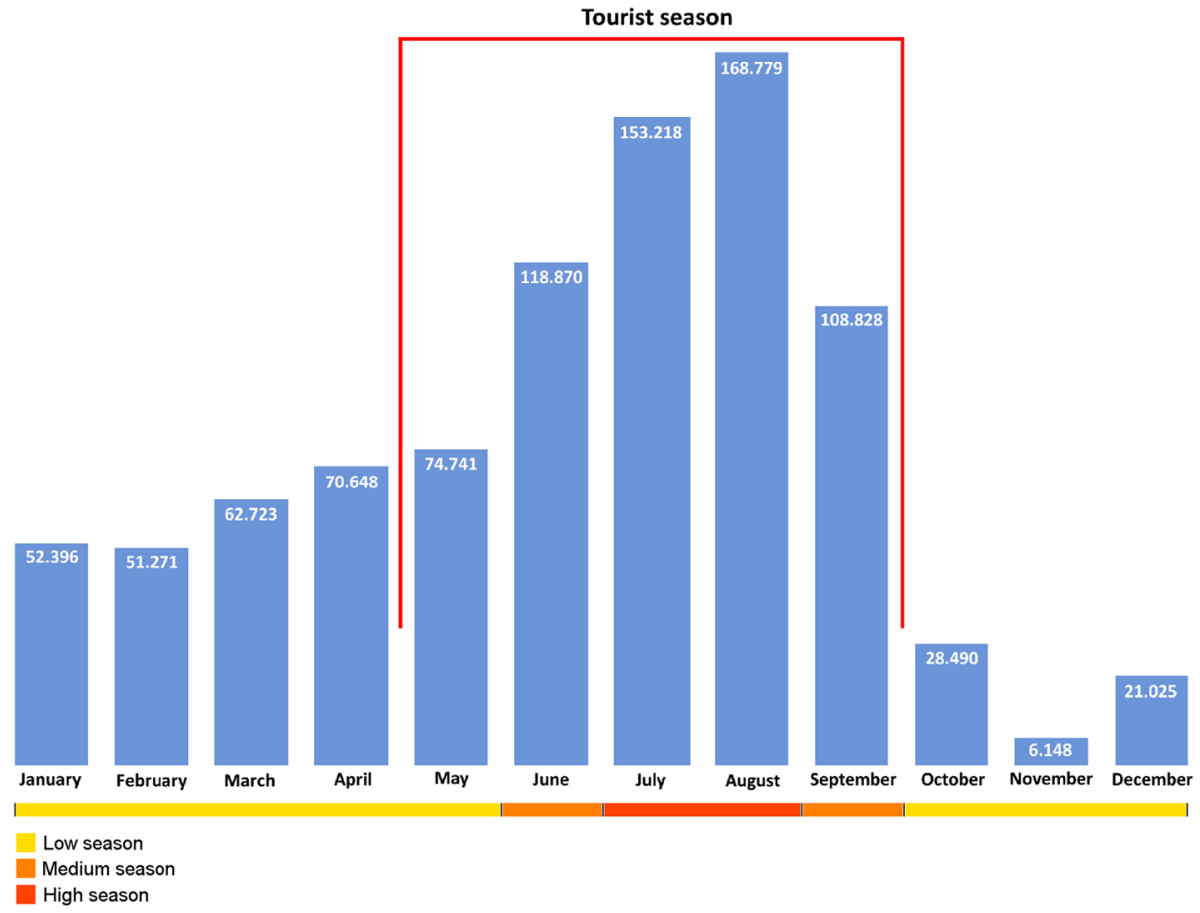

Fig. 5 Official tourist presences in 2012 for the Alassio municipality (Regione Liguria - Settore Ambiente e Settore Politiche Turistiche)

\begin{tabular}{|c|c|c|c|}
\hline $\begin{array}{l}\text { Tourist } \\
\text { presences }\end{array}$ & Low & Moderate & High \\
\hline Low season & Low Risk & Low Risk & Low Risk \\
\hline Medium season & Low Risk & $\begin{array}{l}\text { Moderate } \\
\text { Risk }\end{array}$ & $\begin{array}{l}\text { Moderate } \\
\text { Risk }\end{array}$ \\
\hline High season & $\begin{array}{l}\text { Moderate } \\
\text { Risk }\end{array}$ & High Risk & High Risk \\
\hline
\end{tabular}

Fig. 6 Matrix of risk (RR-matrix) obtained combining $\mathrm{RH}$-index and tourist presences 


\section{Results}

\subsection{Web camera dataset and climate wave}

Web camera images analysis was conducted for twelve months on the investigated beach. The correspondence between climate wave and recorded rip currents genesis was evaluated collecting wave parameters from Capo Mele buoy yearly data, described in Table 5. The table reports mean values for $H_{s}, T_{m}$ and $\theta_{m}$ in correspondence to 28 days during which rip currents were perceived using a web camera. The data assessment results show rip currents development for $H_{s}$ values among 0.50 and $1.34 \mathrm{~m}$ with $T_{m}$ values between 4.7 and $7.0 \mathrm{~s}$, while $\theta_{m}$ has a range of approximately 80 degrees from SE to SW.

Rip current detection was performed, thanks to a time exposure technique (timex images) to make the rip currents flows more visible. To demonstrate this, Fig. 7 shows six rip currents flows from April 2012 to March 2013; images (a) and (b) are filmed on 18 April and 25 June 2012 and they show four seaward flows. In frames (c), (d) and (f), we see rip currents orthogonal to the coastline and are easily identifiable. In October [frame (d)],

Table 5 Climate wave offshore conditions by Capo Mele buoy on correspondence of rip currents detected by web camera

\begin{tabular}{llll}
\hline Date & $H_{s}(m)$ & $T_{m}(s)$ & $\theta_{m}\left({ }^{\circ}\right)$ \\
\hline 18 April 2012 & 1.26 & 6.4 & 198 \\
22 May 2012 & 1.13 & 7.0 & 227 \\
23 May 2012 & 0.96 & 6.9 & 227 \\
25 June 2012 & 0.78 & 6.2 & 202 \\
2 July 2012 & 0.90 & 5.8 & 201 \\
3 July 2012 & 0.90 & 5.7 & 201 \\
16 July 2012 & 0.97 & 5.6 & 209 \\
21 July 2012 & 0.73 & 5.0 & 195 \\
22 July 2012 & 0.67 & 5.3 & 160 \\
31 July 2012 & 0.78 & 5.0 & 202 \\
7 August 2012 & 0.75 & 4.8 & 201 \\
8 August 2012 & 0.43 & 4.7 & 187 \\
8 October 2012 & 0.52 & 4.7 & 170 \\
9 October 2012 & 0.62 & 4.8 & 192 \\
22 October 2012 & 0.50 & 5.6 & 175 \\
23 October 2012 & 0.55 & 5.9 & 203 \\
5 December 2012 & 1.34 & 6.9 & 204 \\
6 December 2012 & 1.04 & 6.5 & 185 \\
7 December 2012 & 0.63 & 6.17 & 183 \\
8 December 2012 & 0.98 & 5.6 & 152 \\
9 December 2012 & 0.75 & 4.9 & 197 \\
10 December 2012 & 0.97 & 5.8 \\
12 January 2013 & 0.93 & 6.0 & 193 \\
15 January 2013 & 0.97 & \\
10 February 2013 & 0.65 & 0.4 & 164 \\
27 February 2013 & 0.69 & 5.3 & 16 \\
\hline
\end{tabular}

Wave parameters are referred to medium values calculated on filmed timeline 


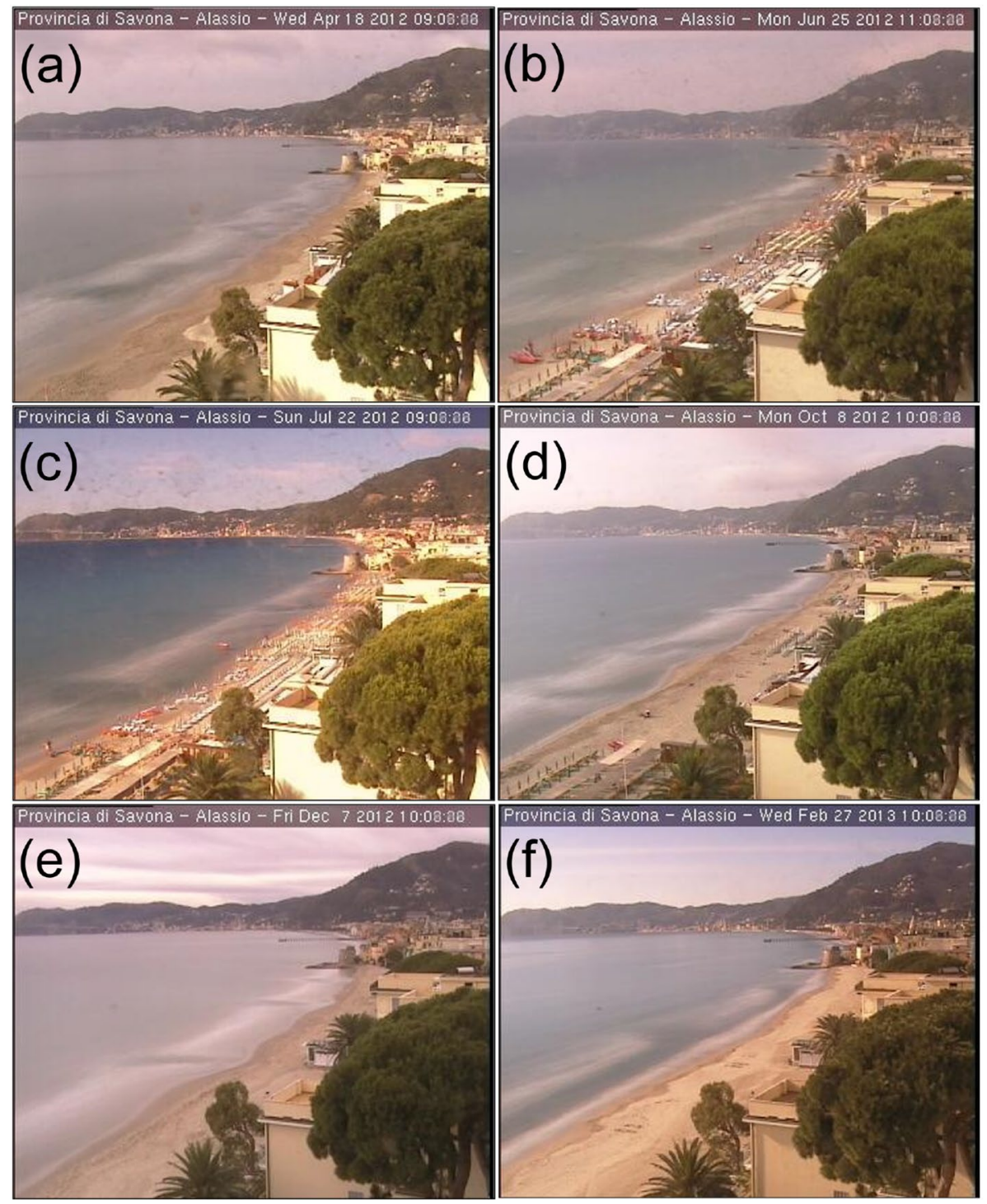

Fig. 7 Rip current events recorded by web camera using timex images processing. a, b July results. c, d December results; in both cases, images have been illustrated using the previously method on fixed time ranges

three equidistant rip currents were detected, but their flow was not orthogonal to the beach line. On 7 December 2012 (e) and on 27 February 2013 (f), timex analysis shows a similar rip flow behaviour; this similarity was also observed on 22 July 2012 (c). 

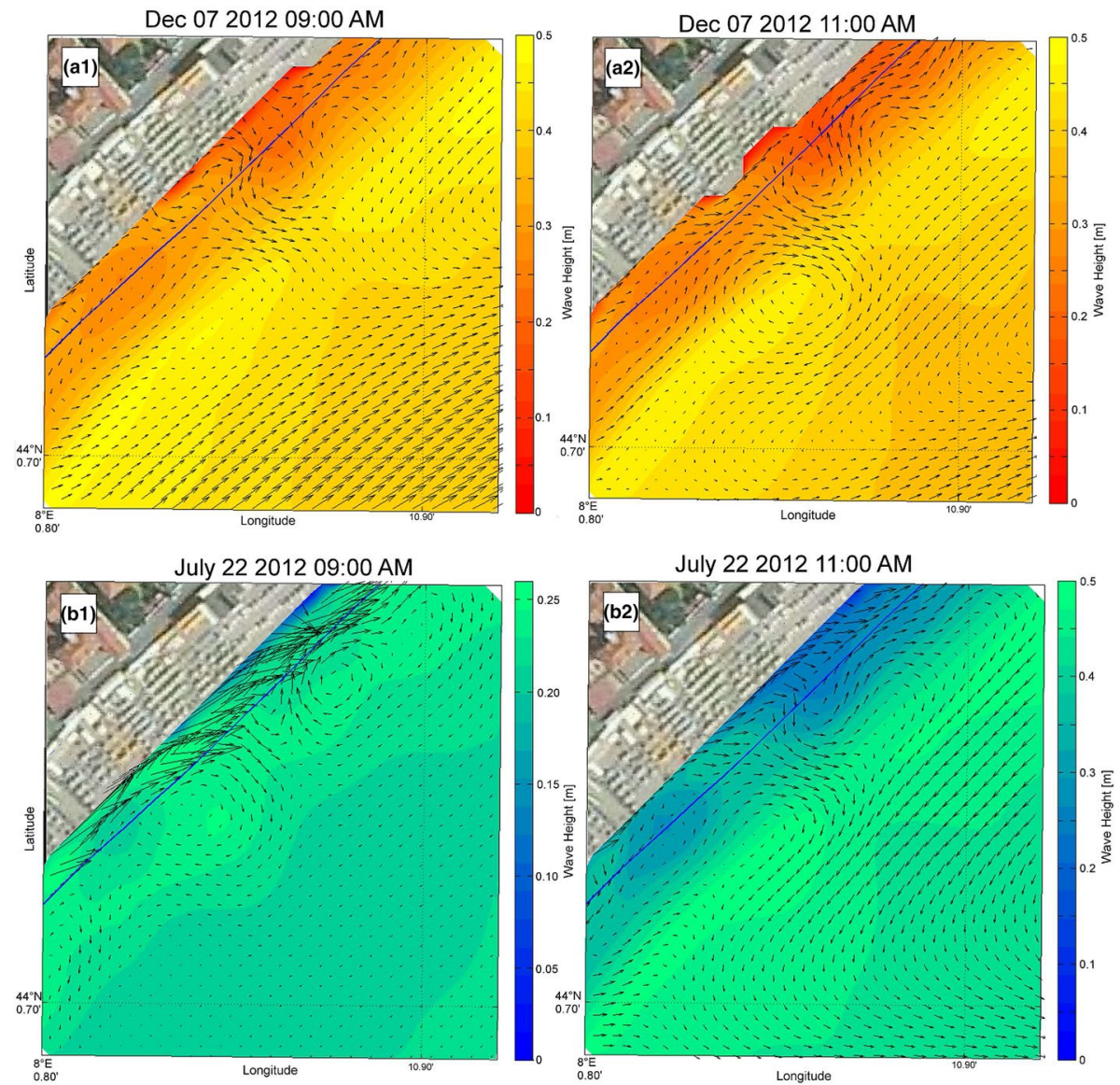

Fig. 8 Focus on hydrodynamic XBeach results for the investigated area: July (a1, a2) and December (b1, b2) 2012. Rip currents behaviour is indicated by black arrows and its magnitude is proportional to the arrows dimension; blue continuous line represents coastline

\subsection{XBeach simulations}

As described in the previous section, to better analyse the rip currents features recorded by web camera, two cases (July 2012 and December 2012) were simulated using the 2DH coastal model XBeach. The output from XBeach model provides the reliable results in both considered cases as they correspond to the rip currents recorded by web camera. The results describe incident wave height and flow direction along the beach (Fig. 8). Figure 8 refers to the time steps elaborated by the XBeach model at 9 AM and at 11 AM on 22 July 2012, at 9 AM and 11 AM on 7 December 2012. Figure 8 illustrates the presence of flow rotation close to the coastline during the previously mentioned time steps, highlighting how wave height is lower in the rip neck than in the feeder zone. Velocities display mean values between 0.3 and $0.8 \mathrm{~ms}^{-1}$ in both simulations. 


\subsection{Rip currents hazard and risk}

We applied the proposed approach for rip current hazard assessment on the Alassio beach, along the western Ligurian coast. Wave parameters and rip currents correspondence, detected by camera dataset and described in the previous section, were used to evaluate when rip currents could develop during the year (Figs. 2, 3, 4). A yearly investigation has reported that $H_{s}$ values, among 0.5 and $1.34 \mathrm{~m}$, occur at 203 days, while $T_{m}$ among 4.7 and $7.0 \mathrm{~s}$ and $\theta_{m}^{\circ}$ among $151^{\circ} \mathrm{N}$ and $227^{\circ} \mathrm{N}$ occur for 90 and 121 days. Using the same range described above, tourist seasonal wave data analysis revealed 60 days of $H_{s}, 62$ days for $T_{m}$ and 41 days for $\theta_{m}^{\circ}$. Based on our approach, both $H_{s}$ and $T_{m}$ (hazard descriptors) show a moderate probability of occurrence during the tourist season. Term $\theta_{m}^{\circ}$ has a low probability of occurrence. Thus, Alassio beach displays a moderate level of rip hazard. Differently, considering the annual dataset of wave parameters, $T_{m}$ and $\theta_{m}^{\circ}$ show a moderate probability of occurrence whereas $H_{s}$ shows a high probability of occurrence. Therefore, the level of rip hazard at the annual scale is high. Combining $R H$ with tourist presences $\left(X_{0}\right)$, we also obtained an evaluation of the rip currents risk $(R R)$ on the Alassio beach. $R R$ is low in lowtourist season, moderate in middle-tourist season and high in high-tourist season (Fig. 9).

\section{Discussion}

\subsection{Rip current monitoring}

The first part of this study was focused on rip currents behaviour in relation to coastal hydrodynamics conditions. Camera-recorded images showed that rip currents are a common phenomenon occurring on the north side of Alassio beach. Thanks to the coastal video-monitoring, 28 cases of rip currents genesis were identified on time laps between the 1 April 2012 and the 31 March 2013. In detail, rip currents flows were identified along filmed area by means of Timex images. Offshore wave analysis conducted using the Capo Mele Buoy database shows a clear correspondence between wave parameters and rip current genesis. In accordance with the literature (Brander 1999; Scott et al. 2011), they occur under moderate-energy conditions, nevertheless, in the Mediterranean environment, the

(a)

\begin{tabular}{|c|l|l|l|}
\hline $\begin{array}{l}\text { Tourist } \\
\text { presences }\end{array}$ & Low & Moderate & High \\
\hline Low season & & $\begin{array}{c}\text { Alassio } \\
\text { beach }\end{array}$ & \\
\hline Medium season & & $\begin{array}{c}\text { Alassio } \\
\text { beach }\end{array}$ & \\
\hline High season & & $\begin{array}{c}\text { Alassio } \\
\text { beach }\end{array}$ \\
\hline
\end{tabular}

(b)

\begin{tabular}{|c|c|c|c|}
\hline $\begin{array}{l}\text { RH-Index } \\
\text { Tourist } \\
\text { presences }\end{array}$ & Low & Moderate & High \\
\hline Low season & & & $\begin{array}{c}\text { Alassio } \\
\text { beach }\end{array}$ \\
\hline Medium season & & & $\begin{array}{l}\text { Alassio } \\
\text { beach }\end{array}$ \\
\hline High season & & & $\begin{array}{c}\text { Alassio } \\
\text { beach }\end{array}$ \\
\hline
\end{tabular}

Fig. 9 Matrix of risk ( $R R$-matrix) applied in the Alassio beach. $R H$-index is different by considering tourist season dataset (a) or yearly dataset (b). Anyhow, risk levels are the same 
tidal level factor is not considered decisive on rip current circulation assessment. Moreover, following Murray et al. (2013), Castelle et al. (2016), investigated rip currents can be classified as "flash rip": they occur when the beach was generally uniform alongshore in a shore-attached terrace state with dominant plunging breakers. This, is a near-normal wave incidence, and the rip currents are episodic and unpredictable, therefore, an increasing risk of drowning for bathers.

The web camera analysis used here is a suitable tool for the study of rip currents even though cameras need to be placed in an area where albedo effects and, more in general, weather conditions do not affect the recording. The use of snapshots is often, is insufficient to identify rip currents: the employment of timex methods is more useful given that it can discern rip currents flow. Data collected were also used for a rip currents evaluation by means of XBeach modelling. The model results from July and December 2012 show the genesis of rip currents with velocity values around $0.5 \mathrm{~ms}^{-1}$ located where they were observed by video monitoring in the first place. Rip currents velocity values are comparable to those observed by Wright and Short (1984) and Bowman et al. (1988), respectively, in the first, the beach can be classified as intermediate transverse bar under medium wave condition. In the second, Herzliyya littoral (Israel) is transverse bar beach with intermediate/transitional state and wave conditions show values between 0.3 and $1.1 \mathrm{~m}$ for $\mathrm{Hs}$ and between 3 and $5 \mathrm{~s}$ for Ts. The highest velocities are detected in the rip neck, while the lowest velocities are in the rip head when the flow expands and decreases in intensity (McKenzie 1958; Sonu 1972; Short and Hogan 1994; Masselink and Hegge 1995; Aagaard et al. 1997; Short 1999). The XBeach model application produced good results for the rips development study giving a qualitative evaluation of the hydrodynamic processes.

\subsection{Rip hazard and risk assessment}

According to Bowman et al. (1988), Benassai et al. (2017) and Dusek et al. (2011), the results show that rip currents occur under moderate conditions, when a significant wave height $\left(H_{s}\right)$ is between 0.50 and $1.34 \mathrm{~m}$ with mean direction ranging from $150^{\circ}$ and $227^{\circ} \mathrm{N}$. Moderate wave conditions increase swimmers' risk because their self-confidence causes them to underestimate the hazard level. Rip currents are one of the main hazards for bathers, Brighton et al. (2013), Castelle et al. (2016) and Ferrari et al. (2019), and thus, the development of a rip currents hazard assessment and prediction method is a well-known challenge for coastal scientists (Kumar and Prasad 2014; Austin et al. 2012; Brander and MacMahan 2011; Engle 2002). However, many proposed approaches are based on rescue and/or accidents data and are not suitable for a quick hazard assessment. Moreover, reliable accident statistics are often limited if not absent. For example, along the Italian coasts, which are among the most popular tourist beaches in the world, no reliable statistics dataset are available. We can find data on the fatal accidents, but they are not indicative because they often include all kinds of accidents on the beach (e.g. heat stroke, heart attack). Data on drownings usually do not supply additional information on accidents dynamics (e.g. sea conditions) and place (e.g. sea, river, lake or swimming pool). In Funari et al. (2016), an accidents statistic on drownings in the sea waters is provided. However, data are reported at the regional scale, and they are not useful as a support for lifeguard activity. Thus reason, the rip hazard assessment method proposed here is not based on accident statistics but on wave boundary conditions. Thanks to a rip currents video monitoring conducted on an annual time scale, we found that wave boundary conditions are responsible for rip currents development. In this way, considering $H_{s}, T_{m}$, and $\theta_{m}^{\circ}$, we could define the $R H$-index for 
the considered beach. An interesting point is the different hazard levels observed considering annual time scale (high) and tourist season time scale (moderate). Indeed, even if the tourist season is generally the reference value concerning beach safety, it is important to highlight how Ligurian beaches (and Mediterranean beaches in general) are also usually frequented in low and medium season by bathers and by those who practice water sports. This aspect is important in terms of beach safety and management.

The use of wave parameters allows a quick connection between the rip hazard assessment and marine forecasts. Indeed, the proposed approach offers a quick evaluation of $\mathrm{RH}$ index based on forecasted wave conditions. The $R H$-index can also be used to evaluate rip currents risk $(R R)$. Therefore, as described in the methods section, a risk evaluation is possible using the tourist presence as an index of possible elements at risk. The matrix of risk obtained shows how risk increases with increasing the tourist presence. This point appears banal but is the essence of risk definition (Fell et al. 2008); this point supports the validity of this proposed approach.

\subsection{Beach management implications}

The large and rapidly expanding tourism activities in the coastal environment impose an urgent need of both beach safety and sea bathing risk zoning (Ferrari et al. 2019). Following (Brander 1999; Pranzini 2015), local managers should provide information to beachgoers about the rips hazard to reduce hazard level for Alassio beach water users. Safety signs in correspondence to beach access points should be used in patrolled and unpatrolled beaches. Signalling is the cheapest action to prevent risk on beaches (Teixeira 2014; Mucerino et al. 2019). For a higher efficiency, the symbols used should outline different situations according to ISO 201712 international directives and considering local regulations. Rip currents often occur in moderate sea conditions, precisely where and when beachgoers feel more confident. Many visitors from inland areas and international tourists lack a certain sea experience and knowledge. In addition, under certain circumstances, they may not be able to read beach warning signs or understand the hazard flag system (Leatherman 2017). These features must be considered because rip currents often occur in tourist season when the beaches are most crowded. Moreover, in Italy, beach safety skills reached a high level, and lifeguards need new tools to obtain a further improvement in drowning risk prevention (Funari and Giustini 2011). The proposed approach could provide suitable application to evaluate rip hazard and beachgoers exposure to rip risk. Indeed, the proposed approach can be implemented into a weather forecasting system in order to provide rip currents hazard predictions. This paper also highlighted the necessity to create a national database of incidents caused by rip currents along the Italian coasts as already conducted in the UK (Scott et al. 2014) to allow a more reliable classification of rip currents risk.

\section{Conclusions}

In this paper, an expeditious rip hazard and risk assessment is proposed, based on probability theory, that considers wave boundary conditions and field data observation. In order to evaluate rip currents hazard, web camera data analysis was performed using timex elaboration on yearly observations and compared with offshore wave conditions. The results present a clear correspondence between rip currents development and wave parameters range. 
The XBeach model was computed to obtain an indicative evaluation of the velocities magnitude of seaward flow in two cases during summer and winter.

Based on this analysis, it was possible to apply the probabilistic calculation, described in this work to identify the level of hazard. Furthermore, the risk for swimmers was determined considering the tourist presence. On Alassio beach, the hazard level $(R H)$ is considered high on an annual time scale, but it is moderate during tourist season. In any case, the risk $(R R)$ for bathers seems to be proportional to tourist presence. Unfortunately, due to the absence of reliable data, it was not possible to obtain a more detailed rip current risk evaluation. This method is suitable because the beach safety tool-a relevant component of beach management - can be employed by beach managers as a support to lifeguards. Official websites, apps and signs can be useful in providing information on rip current risks to local population and summer tourists. In Alassio town, this aspect becomes more important due to the high seaside tourist vocation of the area, and since many summer tourists are not aware of the danger they are actually exposed to. Thus, the proposed approach can be considered a valid tool for hazard and risk evaluation of the rip currents in the Mediterranean environment with a high potential of replication and usability in other contexts.

Acknowledgements The authors would like to thanks Regione Liguria - Settore Ambiente and Settore Politiche Turistiche for supplied topographic and tourism dataset. Thanks are also given to the Municipality of Alassio - Savona for logistic support.

Funding Open access funding provided by Università degli Studi di Genova within the CRUI-CARE Agreement.

\section{Compliance with ethical standards}

Conflict of interest The authors declare that they have no conflict of interest.

Open Access This article is licensed under a Creative Commons Attribution 4.0 International License, which permits use, sharing, adaptation, distribution and reproduction in any medium or format, as long as you give appropriate credit to the original author(s) and the source, provide a link to the Creative Commons licence, and indicate if changes were made. The images or other third party material in this article are included in the article's Creative Commons licence, unless indicated otherwise in a credit line to the material. If material is not included in the article's Creative Commons licence and your intended use is not permitted by statutory regulation or exceeds the permitted use, you will need to obtain permission directly from the copyright holder. To view a copy of this licence, visit http://creativecommons.org/licenses/by/4.0/.

\section{References}

Aagaard T, Greenwood B, Nielsen J (1997) Mean currents and sediment transport in a rip channel. Mar Geol 140(1-2):25-45

Aarninkhof S, Ruessink B, Roelvink J (2005) Nearshore subtidal bathymetry from time-exposure video images. J Geophys Res Oceans 110:C06011

Alexander PS, Holman RA (2004) Quantification of nearshore morphology based on video imaging. Mar Geol 208(1):101-111

Arozarena I, Houser C, Echeverria AG, Brannstrom C (2015) The rip current hazard in Costa Rica. Nat Hazards 77(2):753-768

Austin MJ, Scott TM, Russell PE, Masselink G (2012) Rip current prediction: development, validation, and evaluation of an operational tool. J Coast Res 29(2):283-300

Ballantyne R, Carr N, Hughes K (2005) Between the flags: an assessment of domestic and international university students knowledge of beach safety in Australia. Tour Manag 26(4):617-622 
Barlas B, Beji S (2016) Rip current fatalities on the Black Sea beaches of Istanbul and effects of cultural aspects in shaping the incidents. Nat Hazards 80(2):811-821

Benassai G, Aucelli P, Budillon G, De Stefano M, Di Luccio D, Di Paola G, Montella R, Mucerino L, Sica M, Pennetta M (2017) Rip current evidence by hydrodynamic simulations, bathymetric surveys and UAV observation. Nat Hazards Earth Syst Sci 17(9):1493-1503

Bowman D, Arad D, Rosen D, Kit E, Goldbery R, Slavicz A (1988) Flow characteristics along the rip current system under low-energy conditions. Mar Geol 82(3-4):149-167

Bowman D, Ferri S, Pranzini E (2007) Efficacy of beach dewatering Alassio, Italy. Coast Eng 54(11):791-800

Brander RW (1999) Field observations on the morphodynamic evolution of a low-energy rip current system. Mar Geol 157(3-4):199-217

Brander RW, MacMahan JH (2011) Future challenges for rip current research and outreach. In: Leatherman S, Fletemeyer J (eds) Rip currents, beach safety, physical oceanography and wave modeling. CRC Press, Boca Raton, pp 1-29

Brewster BC (2010) Rip current misunderstandings. Nat Hazards 55(2):161-162

Brighton B, Sherker S, Brander R, Thompson M, Bradstreet A (2013) Rip current related drowning deaths and rescues in Australia 2004-2011. Nat Hazards Earth Syst Sci 13(4):1069-1075

Brignone M, Schiaffino CF, Isla FI, Ferrari M (2012) A system for beach video-monitoring: beachkeeper plus. Comput Geosci 49:53-61

Castelle B, Scott T, Brander R, McCarroll R (2016) Rip current types, circulation and hazard. Earth Sci Rev 163:1-21

Clifford KM, Brander RW, Trimble S, Houser C (2018) Beach safety knowledge of visiting international study abroad students to Australia. Tour Manag 69:487-497

Cortesogno L, Vanossi M (1984) Introduzione alla geologia delle Alpi Liguri. J Integr Biogeogr 9(1):1-49

da Klein A, Santana G, Diehl F, De Menezes J (2003) Analysis of hazards associated with sea bathing: results of five years work in oceanic beaches of Santa Catarina State, southern Brazil. J Coast Res 35:107-116

Davidson M, Aarninkhof S, Van Koningsveld M, Holman R (2006) Developing coastal video monitoring systems in support of coastal zone management. J Coast Res 39:49-56

Drozdzewski D, Roberts A, Dominey-Howes D, Brander R (2015) The experiences of weak and non-swimmers caught in rip currents at Australian beaches. Aust Geogr 46(1):15-32

Dusek G, Seim H, Hanson J, Elder D (2011) Analysis of rip current rescues at Kill Devil Hills. CRC Press, Boca Raton

Engle J (2002) Formulation of a rip current predictive index using rescue data Jason Engle*, James Macmahan, Robert J. Thieke, Daniel M. Hanes and Robert G. Dean* Graduate Assistant, Department of Civil and Coastal Engineering, University of Florida phone:(352) 392-9537 ext-1410; email: engle@ coastal.ufl.edu. In: 2002 national conference on beach preservation technology. Florida Shore \& Beach Preservation Association, Citeseer, p 285

Fell R, Corominas J, Bonnard C, Cascini L, Leroi E, Savage WZ et al (2008) Guidelines for landslide susceptibility, hazard and risk zoning for land-use planning. Eng Geol 102(3-4):99-111

Ferrari M, Ferri S, Pranzini E, Rosas V, Schiaffino CF (2014) Dinamica sedimentaria della spiaggia di Alassio e valutazione dellidoneità dei sedimenti di cava per il suo ripascimento artificiale. Studi costieri 22:125-133

Ferrari M, Carpi L, Pepe G, Mucerino L, Schiaffino C, Brignone M, Cevasco A (2019) A geomorphological and hydrodynamic approach for beach safety and sea bathing risk estimation. Sci Total Environ 671:1214-1226

Funari E, Giustini M (2011) Annegamenti in Italia: epidemiologia e strategie di prevenzione. Istituto superiore di sanità

Funari E, Giustini M, Pezzini D et al (2016) Accidents in recreational waters: towards an integrated strategy of drowning prevention. Rapporti ISTISAN-Istituto Superiore di Sanità (16/10)

Gensini VA, Ashley WS (2010) An examination of rip current fatalities in the United States. Nat Hazards 54(1):159-175

Hartmann D (2006) Drowning and beach-safety management (BSM) along the Mediterranean beaches of Israela long-term perspective. J Coast Res 22:1505-1514

Hasselmann D, Dunckel M, Ewing J (1980) Directional wave spectra observed during JONSWAP 1973. J Phys Oceanogr 10(8):1264-1280

Holland KT, Holman RA, Lippmann TC, Stanley J, Plant N (1997) Practical use of video imagery in nearshore oceanographic field studies. IEEE J Ocean Eng 22(1):81-92

Holman R, Stanley J, Ozkan-Haller T (2003) Applying video sensor networks to nearshore environment monitoring. IEEE Pervasive Comput 2(4):14-21 
Jackson D, Cooper J, Del Rio L (2005) Geological control of beach morphodynamic state. Mar Geol 216(4):297-314

Jiménez J, Osorio A, Marino-Tapia I, Davidson M, Medina R, Kroon A, Archetti R, Ciavola P, Aarnikhof $S$ (2007) Beach recreation planning using video-derived coastal state indicators. Coast Eng 54(6):507-521

Kumar SA, Prasad K (2014) Rip current-related fatalities in India: a new predictive risk scale for forecasting rip currents. Nat Hazards 70(1):313-335

Leatherman SB (2017) Rip current measurements at three South Florida beaches. J Coast Res 33(5):1228-1234

MacMahan JH, Thornton EB, Reniers AJ (2006) Rip current review. Coast Eng 53(2-3):191-208

Markowski AS, Mannan MS (2008) Fuzzy risk matrix. J Hazard Mater 159(1):152-157

Masselink G, Hegge B (1995) Morphodynamics of meso-and macrotidal beaches: examples from central Queensland, Australia. Mar Geol 129(1-2):1-23

McKenzie P (1958) Rip-current systems. J Geol 66(2):103-113

Moran K, Ferner D (2017) Water safety and aquatic recreation among international tourists in New Zealand. Int J Aquat Res Educ 10(1):5

Mucerino L, Albarella M, Carpi L, Besio G, Benedetti A, Corradi N, Firpo M, Ferrari M (2019) Coastal exposure assessment on Bonassola bay. Ocean Coast Manag 167:20-31

Murray T, Cartwright N, Tomlinson R (2013) Video-imaging of transient rip currents on the gold coast open beaches. J Coast Res 65(sp2):1809-1814

Nikuradse J (1950) Laws of flow in rough pipes. National Advisory Committee for Aeronautics, Washington

Pranzini E (2015) La spiaggia: istruzioni per l'uso. Progetto Marittimo-IT.FR-MArittimo I-PERLA, pp 1-40, http://www.progettoperla.eu/wordpress/wp-content/uploads/2015/06/La-Spiaggia_istruzioni -per-luso.pdf

Pugliano G, Robustelli U, Di Luccio D, Mucerino L, Benassai G, Montella R (2019) Statistical deviations in shoreline detection obtained with direct and remote observations. J Mar Sci Eng 7(5):137

Roelvink D, Reniers A, Van Dongeren A, de Vries JT, McCall R, Lescinski J (2009) Modelling storm impacts on beaches, dunes and barrier islands. Coast Eng 56(11):1133-1152

Ruessink B, Walstra D, Southgate H (2003) Calibration and verification of a parametric wave model on barred beaches. Coast Eng 48(3):139-149

Schiaffino CF, Dessy C, Corradi N, Fierro G, Ferrari M (2015) Morphodynamics of a gravel beach protected by a detached low-crested breakwater: the case of Levanto (eastern ligurian sea, Italy). Ital J Eng Geol Environ 15(1):31-39

Scott TM, Russell P, Masselink G, Austin M, Wills S, Wooler A (2011) 14 rip current hazards on large-tidal beaches in the United Kingdom. In: Rip currents: beach safety, physical oceanography, and wave modeling, p 225

Scott T, Masselink G, Austin MJ, Russell P (2014) Controls on macrotidal rip current circulation and hazard. Geomorphology 214:198-215

Shepard F, Emery K, La Fond E (1941) Rip currents: a process of geological importance. J Geol 49(4):337-369

Short AD (1999) Handbook of beach and shoreface morphodynamics. 551.468 HAN

Short A, Hogan C (1994) Rip currents and beach hazards: their impact on public safety and implications for coastal management. J Coast Res 12:197-209

Sonu CJ (1972) Field observation of nearshore circulation and meandering currents. J Geophys Res 77(18):3232-3247

Spiegel SLJMR (2008) Theory and problems of statistics. Schaum's outline series, 4th edn. McGraw-Hill, New York

Teixeira SB (2014) Coastal hazards from slope mass movements: analysis and management approach on the Barlavento Coast, Algarve, Portugal. Ocean Coast Manag 102:285-293

Turner IL, Aarninkhof S, Dronkers T, McGrath J (2004) CZM applications of argus coastal imaging at the Gold Coast, Australia. J Coast Res 20:739-752

Vacchi M, Montefalcone M, Schiaffino CF, Parravicini V, Bianchi CN, Morri C, Ferrari M (2014) Towards a predictive model to assess the natural position of the posidonia oceanica seagrass meadows upper limit. Mar Pollut Bull 83(2):458-466

Van Ormondt M, Van Dongeren A, Briere C, Sembiring L, Winter G, Lescinski J, Swinkels C (2012) Simulating storm impacts and coastal flooding along the Netherlands Coast. Flood Risk 10:28-29

Varnes DJ (1984) Landslide hazard zonation: a review of principles and practice, 3

Vietti RC, Albertelli G, Aliani S, Bava S, Bavestrello G, Cecchi LB, Bianchi C, Bozzo E, Capello M, Castellano $\mathrm{M}$ et al (2010) The Ligurian Sea: present status, problems and perspectives. Chem Ecol 26(S1):319-340 
Wilks J, Pendergast D (2010) International tourists and road safety. In: Drive tourism. Routledge, pp 292-309

Williamson A, Hatfield J, Sherker S, Brander R, Hayen A (2012) A comparison of attitudes and knowledge of beach safety in Australia for beachgoers, rural residents and international tourists. Aust N Z J Public Health 36(4):385-391

Wright L, Short AD (1984) Morphodynamic variability of surf zones and beaches: a synthesis. Mar Geol 56(1-4):93-118

Publisher's Note Springer Nature remains neutral with regard to jurisdictional claims in published maps and institutional affiliations.

\section{Affiliations}

\section{Luigi Mucerino ${ }^{1,3} \cdot$ Luca Carpi $^{1,3} \cdot$ Chiara F. Schiaffino $^{1} \cdot$ Enzo Pranzini $^{2}$. Eleonora Sessa $^{1} \cdot$ Marco Ferrari $^{1,3}$}

Luca Carpi

carpi.luca@edu.unige.it

Chiara F. Schiaffino

chiara.schiaffino@msn.it

Enzo Pranzini

enzo.pranzini@unifi.it

Eleonora Sessa

sessa.eleonora@edu.unige.it

Marco Ferrari

marco.ferrari@unige.it

1 DISTAV Universita' degli studi di Genova, Corso Europa, 26, 16132 Genoa, Italy

2 DST Universita' di Firenze, Via Micheli 6, 50121 Florence, Italy

3 Geoscape soc. coop. Spin-off dell’Università di Genova, Via Varese 2, 16122 Genova, Italy 